\title{
Determination of mercury distribution inside spent compact fluorescent lamps by atomic absorption spectrometry
}

\author{
Natalia Rey-Raap, Antonio Gallardo* \\ Departamento de Ingeniería Mecánica y Construcción, Universitat Jaume I de Castellón, Av. de Vicent Sos Baynat s/n, 12071 Castellón de la Plana, España, Spain
}

\section{A R T I C L E I N F O}

Article history:

Received 28 July 2011

Accepted 1 December 2011

Available online $\mathrm{xxxx}$

\section{Keywords:}

Atomic absorption spectrometry

Compact fluorescent lamps

Phosphor powder

Hazardous waste

\begin{abstract}
A B S T R A C T
In this study, spent compact fluorescent lamps were characterized to determine the distribution of mercury. The procedure used in this research allowed mercury to be extracted in the vapor phase, from the phosphor powder, and the glass matrix. Mercury concentration in the three phases was determined by the method known as cold vapor atomic absorption spectrometry. Median values obtained in the study showed that a compact fluorescent lamp contained $24.52 \pm 0.4 \mathrm{ppb}$ of mercury in the vapor phase, $204.16 \pm 8.9 \mathrm{ppb}$ of mercury in the phosphor powder, and $18.74 \pm 0.5 \mathrm{ppb}$ of mercury in the glass matrix. There are differences in mercury concentration between the lamps since the year of manufacture or the hours of operation affect both mercury content and its distribution. The $85.76 \%$ of the mercury introduced into a compact fluorescent lamp becomes a component of the phosphor powder, while more than $13.66 \%$ is diffused through the glass matrix. By washing and eliminating all phosphor powder attached to the glass surface it is possible to classified the glass as a non-hazardous waste.
\end{abstract}

(c) 2011 Elsevier Ltd. All rights reserved.

\section{Introduction}

Nowadays, the most efficient lighting systems to be found on the market consist of discharge or LED (Light-Emitting Diode) technologies. In sectors where the greatest energy consumption is mostly due to lighting, which means in the residential, commercial and public sector, discharge technology is the most commonly used (Sobral et al., 2006). This technology is based on the phenomenon of fluorescence, which is why this type of lamp is commonly known as fluorescent lamps. In order to produce this phenomenon it is necessary to introduce certain chemicals inside the lamp with which produce it, namely, liquid mercury and phosphor powder (Hirajima et al., 2005). Due to the use of this heavy metal, fluorescent lamps are also known as mercury lamps.

Mercury is one of the most toxic elements on Earth (Smocovich, 2000; Wong et al., 2006; Mukherjee et al., 2004). For this reason, the European Commission, under Directive 2002/95/EC on the restriction of the use of certain hazardous substances in electrical and electronic equipment (RoHS), prohibited the use of this substance in electrical and electronic equipment (EEE). As the use of mercury in fluorescent lamps is essential for them to work properly (Raposo et al., 2003), this policy lists them as EEE that may contain mercury. In the case of compact fluorescent lamps (CFLs),

\footnotetext{
* Corresponding author. Tel./fax: +34 964728187

E-mail address: gallardo@emc.uji.es (A. Gallardo).
}

the concentration should not exceed $5 \mathrm{mg}$ per lamp (Gensch et al., 2009).

Part of the mercury introduced into a lamp is used to produce visible light while the other part interacts with the phosphor powder and the glass matrix (Hildenbrand and Denissen, 2000). Consequently, when the device becomes waste, both components are contaminated by this metal (Dang et al., 2002; Hildenbrand et al., 2003; Thaler et al., 1995; Doughty et al., 1995), thereby turning it into hazardous waste that should be treated as such. The management of spent CFL is regulated by Directive 202/96/CE on electrical and electronic equipment and waste management (WEEE). According to this directive, Member States shall ensure that producers recover a minimum of $70 \%$ by average weight per appliance and reuse and recycle over $50 \%$ by average weight per appliance of the component, material and substance.

The main treatment process used in Spain is based on one of the most highly developed methods currently available, i.e., the MRT System in Sweden (Chang et al., 2007a,b). In this system, the spent fluorescent lamps are broken under negative pressure while the phosphor powder is collected at the same time. Electromagnets and densimetric tables are then used to facilitate the separation of the different materials. In a used CFL, most of the mercury is in the phosphor powder, therefore the powder collected is distillated at temperatures above $375^{\circ} \mathrm{C}$, corresponding to the boiling point of mercury (Chang et al., 2007b). Generally, temperatures between 600 and $800{ }^{\circ} \mathrm{C}$ are used to ensure complete removal of mercury due to during the use of the lamp mercury may form oxides 
whose boiling temperatures are higher than those for elemental mercury (Raposo et al., 2003).

The drawbacks of this treatment process is that only the phosphor powder is distilled and that it does not completely remove the phosphor powder attached to the glass and, hence not all the mercury is removed either (Durão et al., 2008). This fact makes the recovery of residual glass obtained in the treatment plant a far more complicated process because, as it contains mercury, it is rejected by companies that could use it as a raw material in their production processes.

In order to achieve the target set out by the legislation it is necessary to improve the current treatment process or find another one which allows more mercury to be removed. The first step toward achieving this aim is to study this category of waste from the point of view of the concentration of mercury. Mercury concentration was determined by the method known as cold vapor atomic absorption. This method is one of the most used for the analysis of mercury content in different types of samples such as soils, water or food (Kagaya et al., 2010; Tuzen et al., 2009; Voegborlo and Adimado, 2010). The process involves chemically reduction of the mercury in its elemental state using a strong reducing agent. Authors such as Dobrowolski and Mierzwa (1992) or more recently Singhvi et al. (2011) used this method to analyze the concentration of mercury in fluorescent lamps.

In this study, the concentration of mercury in the CFL components was analyzed in order to determine the distribution and the total amount of mercury inside the lamps. The glass toxicity was also determined from the point of view of the concentration of mercury.

\section{Experimentation}

The determination of the mercury distribution inside a waste CFL includes the study of mercury vapor that has not reacted, mercury that has reacted with the phosphor powder, and the mercury diffused through the glass matrix. A methodology allowing the

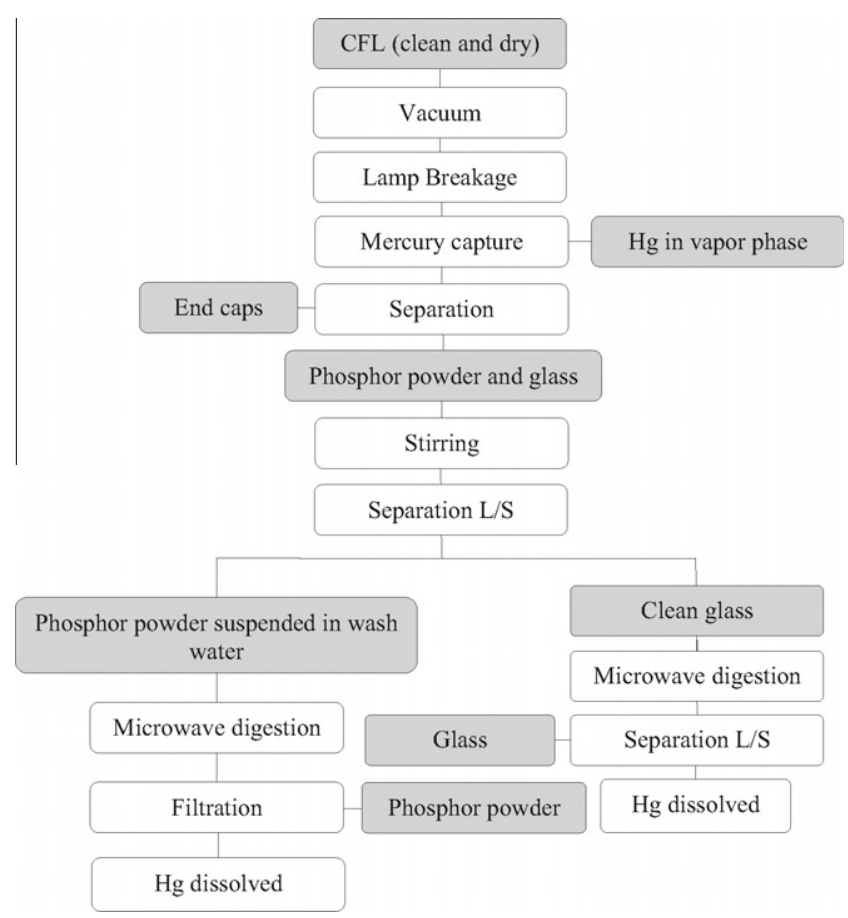

Fig. 1. Schematic diagram of the experimental methodology used to determine mercury distribution. separation of each component was established in order to determine the concentration of mercury by atomic absorption spectroscopy (AAS) as it is shown in Fig. 1.

Since the amount of mercury introduced into a lamp can vary greatly from one unit to another (Bussi et al., 2010), in this study the distribution of mercury was determined in Master PL-C CFL that had the same characteristics (dimensions and watts), with the aim of obtaining a representative mean value of such devices. The toxicity of the glass obtained from each broken lamp was studied by applying UNE-EN 12457-1 on characterization of waste: leaching.

\subsection{Instrumentation}

Mercury vapor was captured with a Watson Marlow 505S/RL peristaltic pump with variable-speed manual control and a PTFE tube with an internal diameter of $7 \mathrm{~mm}$ and an outer diameter of $10 \mathrm{~mm}$. Separation of the phosphor powder and the glass was performed in an SBS/ABT-6 shaker with polypropylene bottles with a volume of $1000 \mathrm{ml}$. Mercury extractions were performed in a Milestone 1200 MEGA microwave digester with an EM-45 vapor extraction module and Model 240 remote terminal, equipped with PTFE closed vessels. Finally, the mercury concentration was analyzed by using a Perkin-Elmer Analyst 100 spectrometer, equipped with a Flow Injection Analysis System (FIAS). A Perkin-Elmer mercury $(\mathrm{Hg})$ hollow cathode lamp that operated at $30 \mathrm{~mA}$ and a selected wavelength of $235.7 \mathrm{~nm}$, and a quartz cell were both used during the experiments. All liquid samples were analyzed with a WTW pH330.

\subsection{Reagents and materials}

All chemicals used during the experiments were of analytical grade. Reagent water from Panreac (type 2) for use in laboratory analyses was employed in all samples. The following reagents were also used: $37 \% \mathrm{v} / \mathrm{v}$ hydrochloric acid $(\mathrm{HCl})$ from Panreac, $65 \% \mathrm{v} / \mathrm{v}$ nitric acid $\left(\mathrm{HNO}_{3}\right)$ from Panreac, 30\% v/v hydrogen peroxide $\left(\mathrm{H}_{2} \mathrm{O}_{2}\right)$ from Panreac, sodium borohydride $\left(\mathrm{NaBH}_{4}\right)$ from Fluka, sodium hydroxide $(\mathrm{NaOH})$ from Panreac, potassium permanganate $\left(\mathrm{KMnO}_{4}\right)$ from Panreac, and Perkin-Elmer Pure Plus standard solution containing $10 \mathrm{mg} / \mathrm{l}$ of mercury.

According to the manufacturer, the lamps analyzed contained about $1.4 \mathrm{mg}$ of mercury and weighed $52.92 \mathrm{~g}$. Each lamp consisted of four narrow parallel tubes with a length of $130.7 \mathrm{~mm}$ and a diameter of $13.5 \mathrm{~mm}$. All of them were gathered from a waste collection point.

\subsection{Sample preparation}

The most common technique used to determine mercury is AAS, but it requires samples that can be analyzed as a liquid solution. Since the aim of this study was to determine the mercury vapor and mercury incorporated within a solid (phosphor powder and glass matrix), it was necessary to apply mercury extraction techniques that allow it to be dissolved in a liquid solution. In this study microwave digestion was used as an extraction technique.

\subsubsection{Capture of mercury in the vapor phase}

Each clean dry CFL was placed in a sealable plastic bag. One end of the PTFE tube from the peristaltic pump was attached to the bag before closing it. Once assembled, the closure of the bag was checked to ensure no air could enter or escape. The other end of the tube was left open. A vacuum was applied inside the bag using a peristaltic pump at full speed (220 rpm). It was easy to identify the moment a vacuum was reached because the plastic bag was completely adhered to the lamp. During operation of the peristaltic 
Table 1

Optimized program for the digestion of liquid and solid samples.

\begin{tabular}{lcc}
\hline Stage & Time $(\mathrm{min})$ & Power (watts) \\
\hline 1 & 5 & 250 \\
2 & $\mathrm{I}$ & 0 \\
3 & 10 & 250 \\
4 & 5 & 450 \\
Ventilation & 5 & Off \\
\hline
\end{tabular}

pump, $40 \mathrm{ml}$ of a mixed acid solution were pipetted into a squeeze bottle. The mixture of acids was prepared with $\mathrm{HCl}$ and $\mathrm{HNO}_{3}$ at a ratio of $1: 1$ by volume. By using this combination of strong and oxidant acids mercury reacts to form water soluble salts (Capri, 1997).

Once the vacuum had been reached, the free end of the PTFE tube was adapted to a bent glass tube of a smaller diameter inserted into the squeeze bottle. The glass tubes of the lamp were then broken by hitting them with a rubber mallet. The maximum airflow rate of the peristaltic pump allowed the mercury vapor to pass through the PTFE tube and bubble into the acid mixture. This acid mixture with the captured mercury was poured into a $100 \mathrm{ml}$ flask, leveled with reagent water and stored at $4{ }^{\circ} \mathrm{C}$ until it was time to analyze it. The end cap of the lamp was removed while the glass and phosphor powder were weighed and broken into smaller pieces to facilitate their separation.

\subsubsection{Extraction of mercury in phosphor powder}

All the lamp glass with phosphor powder attached to it together with reagent water weighting twice as much as the glass were placed into the shaker bottles with a stirring speed of $10 \mathrm{rpm}$ for $24 \pm 0.5 \mathrm{~h}$. After a day, the solid (glass) was separated from the liquid (wash water with suspended phosphor powder). On the other hand, the bag that contained the lamp during breakage was washed manually with reagent water to retrieve the phosphor powder released during breakage. This water was mixed with the wash water obtained in the stirring process so that all the phosphor powder, corresponding to one lamp, was suspended in the final water.

The extraction of the mercury from the phosphor powder was performed by microwave digestion. The times and powers for each stage of the program used for digestion are shown in Table 1. The program recommended introducing $5 \mathrm{~g}$ of the liquid sample, and using $6 \mathrm{ml}$ of $\mathrm{HNO}_{3}, 3 \mathrm{ml}$ of $\mathrm{HCl}$ and $0.25 \mathrm{ml}$ of $\mathrm{H}_{2} \mathrm{O}_{2}$ as a digest mixture. After digestion, each sample was placed in a flask, leveled with reagent water, and stored at $4{ }^{\circ} \mathrm{C}$ until analysis.

\subsubsection{Extraction of the mercury in the glass matrix}

After separating out the glass (now free of phosphor powder), it was dried at room temperature during $24 \mathrm{~h}$ wrapped in laboratory bench paper. Mercury extraction was performed by microwave digestion. The program specifications were the same as for the digestion of water (Table 1 ), although in this case $1.5 \mathrm{~g}$ of solid sample were introduced with the same digest mixture containing $6 \mathrm{ml}$ of $\mathrm{HNO}_{3}, 3 \mathrm{ml}$ of $\mathrm{HCl}$ and $0.25 \mathrm{ml}$ of $\mathrm{H}_{2} \mathrm{O}_{2}$. After digestion, the digest mixture was placed in a flask, leveled with reagent water, and stored at $4{ }^{\circ} \mathrm{C}$ until analysis.

\subsection{Leaching test}

The leaching test was carried out as established in UNE-EN 12457-1. Characterization of waste: leaching. It was applied to glass from broken lamps with and without phosphor powder attached to it. The process involves leaving the glass with a particle size of less than $4 \mathrm{~mm}$ in a shaker for $24 \pm 0.5 \mathrm{~h}$ with reagent water at a liquid-solid ratio of $21 / \mathrm{kg}$ and a speed of $10 \mathrm{rpm}$. After stirring, the two phases were separated. The supernatant was filtered using a pore size of $0.45 \mu \mathrm{m}$, introduced into a $100 \mathrm{ml}$ volumetric flask, and leveled with reagent water. Finally, it was stored at $4{ }^{\circ} \mathrm{C}$ until analysis by the cold vapor AAS method, as specified by UNE-EN 1483 Water quality. Determination of mercury. Method of atomic absorption spectrometry. Glass obtained from a broken lamp with phosphor powder attached to its surface and clean glass obtained after removing all the phosphor powder by washing the surface with reagent water were both tested. The limits of acceptance at a landfill, in accordance with the results of this test, are stated in Decision 2003/33/EC establishing the criteria and procedures for the acceptance of waste at landfills pursuant to Article 16 and Annex II to Directive 1999/31/EC.

\subsection{Reagents and standards preparation}

For the analysis of mercury, the carrier solution used was hydrochloric acid at $3 \%$ by volume. This was prepared by introducing $500 \mathrm{ml}$ of reagent water into a $1000 \mathrm{ml}$ flask, then adding $30 \mathrm{ml}$ of hydrochloric acid with a purity of $37 \%$ and which had been leveled up with reagent water. The reducing agent used was a basic aqueous solution of sodium borohydride at $0.2 \%$ and with $0.05 \%$ of soda. It was prepared by introducing $250 \mathrm{ml}$ of reagent water into a $500 \mathrm{ml}$ volumetric flask, $1 \mathrm{~g}$ of $\mathrm{NaBH}_{4}$ and $0.25 \mathrm{~g}$ of $\mathrm{NaOH}$. The flask was stirred manually until all solid material had been completely diluted. Finally, it was leveled with reagent water and filtered under a vacuum using a filter with a pore size of $0.45 \mu \mathrm{m}$. This solution was prepared just prior to being used, as it cannot be stored. The standards were prepared in $100 \mathrm{ml}$ flasks in which a $3 \%$ solution of hydrochloric acid was introduced, together with the necessary amount of standard $10 \mathrm{ppm}$ solution of mercury in order to achieve the desired concentration. The blank was prepared with the same standard acidic solution (3\% hydrochloric acid) but without adding a standard mercury solution. The blank was analyzed every 10 samples.

\subsection{Mercury analysis}

Before performing the analyzes, each sample was filtered under a vacuum using filters with a pore size of $0.45 \mu \mathrm{m}$, as indicated by the specifications of the analytical measurement equipment. Once filtered, the $\mathrm{pH}$ was measured to ensure that it was below two, and then all samples were stored at $4{ }^{\circ} \mathrm{C}$ until $1 \mathrm{~h}$ before the analysis, so that by the time testing began they were at room temperature. The concentration of mercury was determined by the cold vapor AAS method using the FIAS with the specifications listed in Table 2. For each sample, three replicates were performed in aliquots of $0.5 \mathrm{ml}$, which yielded a representative mean value for each lamp tested. All tests were performed considering the peak area.

\subsection{Samples analysis results}

The concentration of mercury per lamp unit captured in the vapor phase was calculated as:

$C_{\mathrm{v}}=C_{\mathrm{vm}} \times V_{\mathrm{f}} \times 0.001$

where $C_{\mathrm{v}}=$ concentration of mercury per lamp unit captured in the vapor phase ( $\mu \mathrm{g} / \mathrm{lamp}), C_{\mathrm{vm}}=$ concentration of mercury measured by CVAAS method $(\mu \mathrm{g} / \mathrm{l}), V_{\mathrm{f}}=$ final volume of the solution for CVAAS analysis $(100 \mathrm{ml})$.

The concentration of mercury per lamp unit extracted in the phosphor powder was calculated as:

$C_{\mathrm{p}}=C_{\mathrm{pm}} \times\left(V_{\mathrm{f}} / V_{\mathrm{d}}\right) \times\left(V_{\mathrm{s}} / 1000\right)$

where: $C_{\mathrm{p}}=$ concentration of mercury per lamp unit captured in the phosphor powder $(\mu \mathrm{g} / \mathrm{lamp}), C_{\mathrm{pm}}=$ concentration of mercury mea- 
sured by CVAAS method $(\mu \mathrm{g} / \mathrm{l}), V_{\mathrm{f}}=$ final volume of the solution for CVAAS analysis $(100 \mathrm{ml}), V_{\mathrm{d}}=$ digested sample volume $(5 \mathrm{ml})$, $V_{\mathrm{s}}=$ stirring volume $(\mathrm{ml}$, typically $90 \mathrm{ml})$.

The concentration of mercury per lamp unit extracted in the glass matrix was calculated as:

$C_{\mathrm{g}}=C_{\mathrm{gm}} \times\left(V_{\mathrm{f}} / m_{\mathrm{d}}\right) \times\left(m_{\mathrm{g}} / 1000\right)$

where: $C_{\mathrm{g}}=$ concentration of mercury per lamp unit captured in the glass matrix ( $\mu \mathrm{g} / \mathrm{lamp}), C_{\mathrm{gm}}=$ concentration of mercury measured by CVAAS method $(\mu \mathrm{g} / \mathrm{l}), V_{\mathrm{f}}=$ final volume of the solution for CVAAS analysis $(100 \mathrm{ml}), m_{\mathrm{d}}=$ digested sample mass $(1.5 \mathrm{~g}), m_{\mathrm{g}}=$ glass mass that makes up each lamp ( $\mathrm{g}$, typically $47 \mathrm{~g}$ ).

\section{Results and discussion}

\subsection{Mercury distribution}

Three liquid samples with dissolved mercury were obtained for each CFL analyzed. The mercury contained in each sample corresponds to a different component of the lamp: mercury vapor, mercury in phosphor powder, and mercury in the glass matrix (free of phosphor powder, accomplished by washing it with reagent water). The average and standard deviation of the mercury concentration in each sample (and expressed in ppb) are shown in Table 3.

Mercury concentration in the vapor phase tested in different lamps ranged from 17.73 to $31.30 \mathrm{ppb}$ with a median value of $24.52 \mathrm{ppb}$. The average value of the mercury concentration in phosphor powder was an order of magnitude higher than that of mercury in the vapor phase (204.16 ppb). Finally, the mercury concentration in the glass free of phosphor powder and extracted by microwave digestion was between 14.17 and $23.83 \mathrm{ppb}$, with an average value of $18.74 \mathrm{ppb}$. The difference in mercury concentra-

Table 2

Instrumental parameters of the FIAS-AAS. Pump speed: 120.

\begin{tabular}{lll}
\hline Step & Time $(\mathrm{sec})$ & Valve position \\
\hline Pre-filled & 15 & Filled \\
1 & 10 & Filled \\
2 & 15 & Injection/read \\
\hline
\end{tabular}

Table 3

Mercury concentration of eight CFL obtained by the CV-AAS method.

\begin{tabular}{llll}
\hline No. of CFL & Vapor phase & Phosphor powder & Glass matrix \\
\hline \multicolumn{2}{l}{ Mercury concentration $(\mathrm{ppb})$} & & \\
1 & $20.27 \pm 0.2$ & $180.05 \pm 11.3$ & $14.17 \pm 1.5$ \\
2 & $26.66 \pm 0.3$ & $201.65 \pm 44.9$ & $23.83 \pm 1.1$ \\
3 & $17.73 \pm 1.4$ & $195.66 \pm 13.2$ & $15.63 \pm 0.3$ \\
4 & $22.61 \pm 0.3$ & $226.75 \pm 1.7$ & $18.05 \pm 0.9$ \\
5 & $25.68 \pm 0.1$ & $137.45 \pm 1.8$ & $19.81 \pm 0.2$ \\
6 & $31.30 \pm 0.3$ & $232.07 \pm 0.4$ & $19.86 \pm 0.2$ \\
7 & $23.46 \pm 0.6$ & $227.84 \pm 7.1$ & $19.58 \pm 0.1$ \\
8 & $28.49 \pm 0.8$ & $231.82 \pm 0.7$ & $18.97 \pm 0.1$ \\
Average & $24.52 \pm 3.1$ & $204.16 \pm 23.0$ & $18.74 \pm 2.0$ \\
\hline
\end{tabular}

Table 4

Average mercury masses and distribution of this heavy metal inside CFL.

\begin{tabular}{lcclr}
\hline Phase & $\mathrm{ppb}$ & $\mu \mathrm{g} / \mathrm{lamp}$ & $\mu \mathrm{g} / \mathrm{g}_{\text {glass }}$ & \multicolumn{1}{c}{$\%$} \\
\hline Mercury concentration & & & & \\
Vapor phase & $24.52 \pm 3.1$ & $2.45 \pm 0.3$ & $0.05 \pm 0.01$ & 0.58 \\
Phosphor powder & $204.16 \pm 23.0$ & $364.97 \pm 45.1$ & $7.77 \pm 1.0$ & 85.76 \\
Glass & $18.74 \pm 2.0$ & $58.15 \pm 6.5$ & $1.24 \pm 0.1$ & 13.66 \\
Total & $247.42 \pm 24.6$ & $425.57 \pm 46.5$ & $9.06 \pm 1.0$ & 100.00 \\
\hline
\end{tabular}

Table 5

Comparative distribution of mercury inside different CFL.

\begin{tabular}{|c|c|c|c|}
\hline \multicolumn{4}{|c|}{ Mercury distribution in CFL (\%) } \\
\hline Component & $\begin{array}{l}\text { CFL (this } \\
\text { work) }\end{array}$ & $\begin{array}{l}\text { LFL (Jang et al., } \\
\text { 2005) }\end{array}$ & $\begin{array}{l}\text { CFL (Dos Santos et al., } \\
\text { 2010) }\end{array}$ \\
\hline Vapor phase & 0.58 & 0.02 & - \\
\hline End caps & - & 2.36 & - \\
\hline Phosphor powder & 85.76 & 89.35 & 87.73 \\
\hline Glass & 13.66 & 8.27 & 16.27 \\
\hline
\end{tabular}

tion between the lamps, even thought they were of the same type and from the same manufacturer, confirmed that several other factors also affect both the mercury content inside a lamp and its distribution. Such factors include aspects like the year of manufacture or the hours of operation. However, in all cases it is clear that most of the mercury introduced into a CFL during manufacture is in the phosphor powder when that lamp becomes waste material.

The total concentration of mercury per lamp unit obtained from Eqs. (1)-(3) and their standard deviations are shown in Table 4. It is also shown the total concentration of mercury per mass of glass and the mercury distribution inside the lamp expressed as a percentage.

The amount of mercury detected in the vapor phase was $2.45 \mu \mathrm{g} / \mathrm{lamp}$. As the manufacturer indicates that this type of lamp contains $1.4 \mathrm{mg}$ of mercury, the amount in the vapor phase is $0.17 \%$ of the total. This result agrees with the value of $0.4 \%$ reported in another study (Jang et al., 2005). However, if the total mercury concentration recorded in this study ( $425.57 \pm 46.5 \mu \mathrm{g} / \mathrm{lamp})$ is considered, the percentage is slightly higher than $0.4 \%$ as it is shown in Table 4. In any case, the amount of mercury in the vapor phase in a spent CFL must not exceed $56 \mu \mathrm{g} / \mathrm{lamp}$ (Aucott et al., 2003).

The results obtained in this study can be compared with those found by other authors such as Dos Santos et al. (2010) or Jang et al. (2005). The first author studied the mercury content in CFL using a comparable experimental methodology. However, the second one characterized linear fluorescent lamps (LFL). Even though this is not the same type of lamp, since the mass of the lamp and mercury concentration are known, the results can be extrapolated to a CFL. Results from both studies and those obtained in this one are shown in Table 5.

Table 5 shows that the percentages of phosphor powder obtained in each study are similar. Nevertheless, the small difference is due to the fact that the phosphor powder attached to the glass surface was eliminated in a different way. While the other authors used an acid mixture, in this study only reagent water was used. Using an acid mixture may not only eliminate mercury in the phosphor powder but also the mercury spread throughout the glass matrix.

\subsection{Leaching test}

Results from the leaching test carried out on the glass obtained after breaking the lamp are shown in Table 6.

Table 6

Classification of the glass obtained after breaking the lamp.

\begin{tabular}{ccll}
\hline Waste analyzed & $\begin{array}{l}\text { Concentration } \\
\text { detected }\end{array}$ & $\begin{array}{l}\text { Limit } \\
\text { concentration }\end{array}$ & Type of waste \\
\hline $\begin{array}{c}\text { Glass after } \\
\text { breaking }\end{array}$ & $7.77 \pm 1.0$ & $>0.05$ & $\begin{array}{l}\text { Hazardous waste } \\
\text { Glass after }\end{array}$ \\
washing & $0.043 \pm 0.002$ & $>0.50$ & $\begin{array}{l}\text { Safety landfill } \\
\text { Non-hazardous } \\
\end{array}$ \\
& & $<0.05$ & waste \\
& & Non-safety \\
& & landfill \\
\hline
\end{tabular}


The mercury concentration obtained in the leaching test for glass with phosphor powder was $7.77 \pm 1.0 \mu \mathrm{g} / \mathrm{g}$. This value is higher than the limits allowed by European legislation. For this reason the law requires mercury lamps to be treated in order to reduce the concentration of mercury and thereby prevent it from being deposited in safety landfills. On the other hand, the average concentration of mercury obtained in the leaching test for clean glass was slightly lower than the legal limit, so it would not be considered hazardous waste. Therefore, by washing and eliminating all phosphor powder attached to the glass surface, it becomes possible to decrease the mercury concentration enough not only to allow it to be deposited in a non-hazardous landfill, but for it to be classified as non-hazardous waste.

Therefore, in order to enhance recovery of the glass from mercury lamps, it is necessary to eliminate all traces of phosphor powder so that it can be labeled as non-hazardous waste. By so doing, companies that could use it as raw material in their production processes would not need to be authorized as hazardous waste managers.

\section{Conclusions}

Spent compact fluorescent lamps from the same manufacturer and with the same characteristics were analyzed to determine the distribution of mercury inside them, namely, in the vapor phase, phosphor powder, and glass matrix. The median value of mercury concentration for all lamps was $425.57 \pm 46.5 \mu \mathrm{g} / \mathrm{lamp}$. The variation between samples indicates that the total amount of mercury in the lamps not only varies depending on the characteristics and manufacturer but also on the year and place of manufacture and on the operating hours. However, in all cases it is clear that most of the mercury introduced into a CFL (85.76\%) is in the phosphor powder when the lamp reaches the end of its useful life.

The glass obtained from the broken lamps is classified as hazardous waste. Nevertheless, after removing the phosphor powder attached to the surface, it is possible to reduce the mercury concentration below the legal limit so that it can be categorized as non-hazardous waste.

\section{References}

Aucott, M. et al., 2003. Release of mercury from broken fluorescent bulbs. J. Air Waste Manag. Assoc. 53, 143-151.

Bussi, J. et al., 2010. The recovery and recycling of mercury from fluorescent lamps using photocatalytic techniques. J. Chem. Technol. Biotechnol. 85, 478-484.
Capri, A., 1997. Mercury from combustion sources: a review of the chemical species emitted and their transport in the atmosphere. Water, Air, and Soil Pollut. 98, 241-254.

Chang, T.C. et al., 2007a. The fate and management of high mercury-containing lamps from high technology industry. J. Hazard. Mater. 141, 784-792.

Chang, T. et al., 2007b. Characterization of halophosphate phosphor powders recovered from the spent fluorescent lamps. J. Environ. Eng. Manage. 17, 435439.

Dang, T. et al., 2002. Applications of surface analytical techniques for study of the interactions between mercury and fluorescent lamp materials. Anal. Bioanal. Chem. 373, 560-570.

Dobrowolski, R., Mierzwa, J., 1992. Determination of mercury in fluorescent lamp cullet by atomic absorption spectrometry. Analyst 117, 1165-1167.

Dos Santos, É.J. et al., 2010. Determination of $\mathrm{Hg}$ and $\mathrm{Pb}$ in compact fluorescent lamp by slurry sampling inductively coupled plasma optical emission spectrometry. Microchem. J. 96, 27-31.

Doughty, D.A. et al., 1995. Mercury-glass interactions in fluorescent lamps. J. Electrochem. Soc. 142, 3542-3550.

Durão Jr., W. et al., 2008. Mercury reduction studies to facilitate the thermal decontamination of phosphor powder residues from spent fluorescent lamps. Waste Manage. 28, 2311-2319.

Gensch, C., et al., 2009. Adaptation to scientific and technical progress under Directive 2002/95/EC.

Hildenbrand, V.D., Denissen, C.J.M., 2000. Interactions of thin oxide films with a low-pressure mercury discharge. Thin Solid Films 371, 295-302.

Hildenbrand, V.D. et al., 2003. Reduction of mercury loss in fluorescent lamps coated with thin metal-oxide films. J. Electrochem. Soc. 150, H147-H155.

Hirajima, T. et al., 2005. Feasibility of an efficient recovery of rare earth-activated phosphors from waste fluorescent lamps through dense-medium centrifugation. Sep. Purif. Technol. 44, 197-204.

Jang, M. et al., 2005. Characterization and recovery of mercury from spent fluorescent lamps. Waste Manage. 25, 5-14.

Kagaya, S. et al., 2010. Selective removal of mercury(II) from wastewater using polythioamides. J. Hazard. Mater. 175, 1113-1115.

Mukherjee, A.B. et al., 2004. Mercury in waste in the European Union: sources, disposal methods and risks. Resour. Conserv. Recycl. 42, 155-182.

Raposo, C. et al., 2003. Mercury speciation in fluorescent lamps by thermal release analysis. Waste Manage. 23, 879-886.

Singhvi, R. et al., 2011. Determination of total metallic mercury in compact fluorescent lamps (CFLs). Environ. Forensics 12, 143-148.

Smocovich, M.C., 2000. Emergencias químicas provocadas por mercurio y sus compuestos: su prevención y control. Tesis por la Universidad Nacional de General San Martín.

Sobral, L. et al., 2006. Treatment of mercury bearing fluorescent lamps by using an electrochemical process. CETEM - Centre for Mineral Technology.

Thaler, E.G. et al., 1995. Measurement of mercury bound in the glass envelope during operation of fluorescent lamps. J. Electrochem. Soc. 142, 1968-1970.

Tuzen, M. et al., 2009. Mercury(II) and methyl mercury determinations in water and fish samples by using solid phase extraction and cold vapour atomic absorption spectrometry combination. Food Chem. Toxicol. 47, 1648-1652.

Voegborlo, R.B., Adimado, A.A., 2010. A simple classical wet digestion technique for the determination of total mercury in fish tissue by cold-vapour atomic absorption spectrometry in a low technology environment. Food Chem. 123, 936-940.

Wong, C. et al., 2006. Sources and trends of environmental mercury emissions in Asia. Sci. Total Enrivon. 368, 649-662. 